\title{
Resource recovery and harmless treatment of waste oil-in-water drilling fluid
}

\author{
Chao Tang ${ }^{1,2 \dagger}$, Shui Xiang $\mathrm{Xie}^{3}$ \\ ${ }^{1}$ Engineering and Technology College, Yangtze University, JingZhou 434000, China \\ ${ }^{2}$ Petroleum Engineering College, Yangtze University, Wuhan 430000, China \\ ${ }^{3}$ CNPC Research Institute of Safety \& Environment Technology, Beijing 10000, China
}

\begin{abstract}
Destablization and demulsification is a difficult task for the treatment of waste oil-in-water drilling fluid because of its "three-high" characteristics: emulsification, stabilization and oiliness. At present, China is short for effective treating technology, which restricts cleaner production in oilfield. This paper focused on technical difficulties of waste oil-in-water drilling fluid treatment in JiDong oilfield of China, adopting physical-chemical collaboration demulsification technology to deal with waste oil-in-water drilling fluid. After oil-water-solid three-phase separation, the oil recovery rate is up to $90 \%$ and the recycled oil can be reused for preparation of new drilling fluid. Meanwhile, harmless treatment of wastewater and sludge from waste oil-in-water drilling fluid after oil recycling was studied. The results showed that wastewater after treated was clean, contents of chemical oxygen demand and oil decreased from $993 \mathrm{mg} / \mathrm{L}$ and 21,800 mg/L to $89 \mathrm{mg} / \mathrm{L}$ and $3.6 \mathrm{mg} / \mathrm{L}$ respectively, which can meet the requirements of grade one of "The National Integrated Wastewater Discharge Standard" (GB8978); The pollutants in the sludge after harmless treatment are decreased below the national standard, which achieved the goal of resource recovery and harmless treatment on waste oil-in-water drilling fluid.
\end{abstract}

Keywords: Collaboration demulsification, Harmless treatment, Oil recovery, Recycle, Waste oil-in-water drilling fluid

\section{Introduction}

Oil-in-water drilling fluid, a kind of low density underbalanced water-based drilling fluid with industrial mineral oil or diesel as dispersed phase, fresh water or saline water as continuous phase, has properties of both water-based and oil-based drilling fluid. Which is applied for mass promotion in oilfields of China [1-4]. Taking JiDong oilfield for example, according to monolithic deployment of oilfield exploration and development, annual drilling 200-210 wells, mud volume 170 thousand square meters per year (850 square meters per well calculation), usage of oil-in-water drilling fluid account for $10 \%$, which is 17 thousand square meters per year. If not treated appropriately, it will cause great damage to ecological environment. Moreover, large amount of oil resources may be wasted (oil content in waste oil-in-water drilling fluid is about $20 \%-40 \%$ ), improvement of oilfield environment and sustainable economic development were restricted $[5,6]$.

For waste oil-based drilling fluid, the research in China is mainly focused on the field of oily cuttings treatment, such as thermal desorption technology, high efficient oil removal agent for oily drilling cuttings, mechanical and biological treatment, etc. [7-10]. These technologies are tested and used in YiBin, SiChuan province and SuGeli gas field [11]. But China is lack of effective technical methods for dealing with waste oil-in-water drilling fluid at present. Cement anti-seepage pool or solidification technology are mainly methods adopted in oilfield [12], but as time goes on, it will be easy to cause secondary pollution and environmental risk cannot be eliminated thoroughly. So it is imperative to develop harmless and resource recycling technologies on waste oil-in-water drilling fluid [13].

\section{Materials and Equipments}

\subsection{Main Materials}

Waste oil-in-water drilling fluid was from well NP361 of JiDong oilfield; Demulsifier PR-10, ancillary demulsifier PR-15, Petroleum
This is an Open Access article distributed under the terms of the Creative Commons Attribution Non-Commercial License (http://creativecommons.org/licenses/by-nc/3.0/) which permits unrestricted non-commercial use, distribution, and reproduction in any medium, provided the original work is properly cited.
Received December 14, 2016 Accepted February 14, 2017

${ }^{\dagger}$ Corresponding author

Email: 395450161@qq.com

Tel: +86-0716-8067503 Fax: +86-0716-8067507

Copyright (C) 2017 Korean Society of Environmental Engineers 
ether, carbon tetrachloride, anhydrous sodium sulfate and sodium and sodium chloride, etc. were from Tian He Science and Technology Ltd., Jing Zhou.

\subsection{Main Equipments}

Oil 480 infrared oil content analyzers to measure oil was from Beijing Huaxia Instrument Tech. Co., Ltd.; DR200 COD digestion apparatus and DR 2800 UV-Vis Spectrophotometer to measure COD were from Hach Company, USA; AFS-830A Atomic fluorescence spectrometer to measure heavy metal was from Agilent Technologies; The six-speed rotational viscometer to measure property of drilling fluid was from HengTaiDa mechanical and electrical equipment Co., Ltd. in QingDao; Quadruple filtration apparatus to measure drilling fluid filter loss was from ShanDe Petroleum instrument Co., Ltd. in QingDao; some glass apparatuses, etc.

\section{Methods}

\subsection{Determination of Waste Oil-in-water Drilling Fluid Composition}

A moisture determination device was used to determine the water content of the waste oil-in-water drilling fluid. In this device, the moisture was first extracted with petroleum ether, and then condensed and collected. The water content in the sample was calculated by reading the extracted water volume. The residual content was determined by weighing the dried residue after pumping and filtering the liquid inside. Finally, the oil content was calculated by the dispersion method.

\subsection{Determination of Oil Content}

Determination of oil content in wastewater is based on "Determination of petroleum oils and animal and vegetable oilsInfrared spectrophotometry" (HJ/T 637-2012). Determination of oil content in solid is based on "Determination method for munici- pal sludge in wastewater treatment plant” (CJ/T 221-2005).

\subsection{Determination of Chemical Oxygen Demand (COD)}

Determination of COD is based on "Determination of the chemical oxygen demand- Fast digesition- spectrophotometric method" (HJ/T 339-2007).

\subsection{Determination of Drilling Fluid Properties}

Determination of drilling fluid properties is based on "Field testing of drilling fluids- Part 1: Water-based fluids” (GB/T 16783.1-2006).

\section{Results and Discussion}

\subsection{Composition Analysis of Waste Oil-in-water Drilling Fluid}

The composition of waste oil-in-water drilling fluid from well NP361 of JiDong oilfield was analyzed. The results were shown in Table 1 indicating that water content was 51.83\%; oil content was up to $38 \%$. Because of its high oil content, it gives a good value to be recycled.

\subsection{Oil Recovery Test of Waste Oil-in-water Drilling Fluid}

Certain content of waste oil-in-water drilling fluid was put into erlenmeyer flask, when stirred in magnetic stirrer, a certain amount of demulsifier PR-10 and PR-15 were added in order to make demulsifier and fluid mixed thoroughly. The reaction lasted for $15 \mathrm{mins}$ and the temperature was controlled at $60^{\circ} \mathrm{C}$. After that, the emulsion was separated into three phases (water, oil and solids) as shown in Fig. 1. The upper liquid was poured into glass separating funnel, standing for 20-30 min. Recycled the upper oil and collected the lower water and sludge. The analysis results for the composition of oil, water and solid after three-phase separation were shown in Table 2 .

Table 2 indicated that good oil-water-solid three-phase separation effects can be achieved by the method of physical-chemical

Table 1. Contents of Waste Oil-in-water Drilling Fluid (w, \%)

\begin{tabular}{ccccc}
\hline No. & Types & Water content & Oil content & Solid content \\
\hline $1207-1$ & Diesel-in-water & 51.83 & 38.14 & 10.03 \\
\hline
\end{tabular}

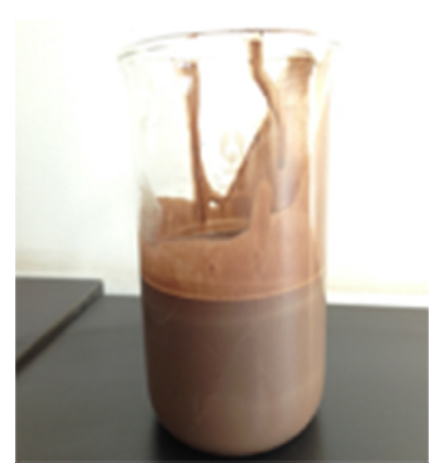

(a)

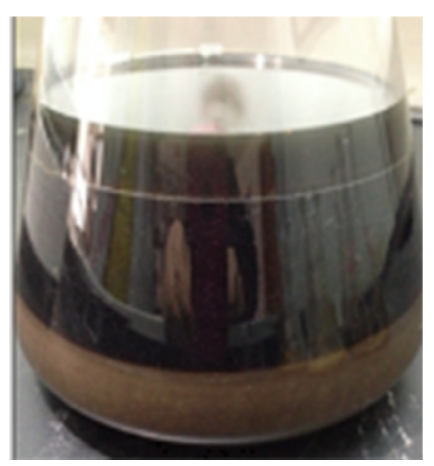

(b1)

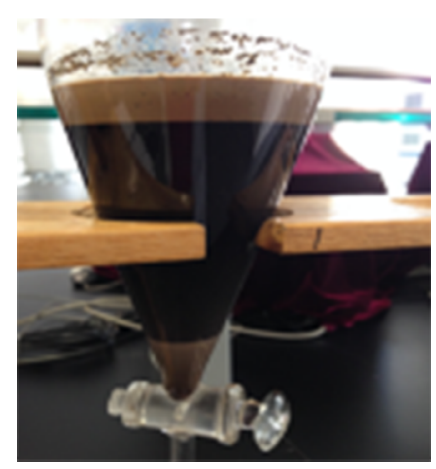

(b2)

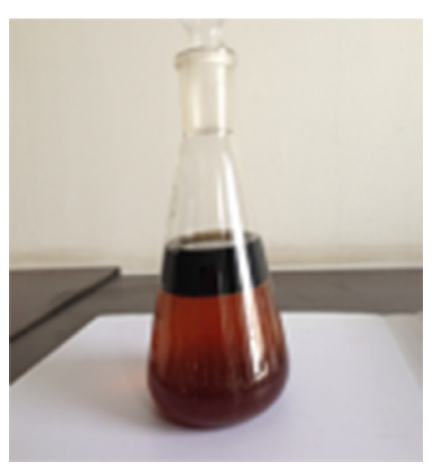

(c)

Fig. 1. Before and after oil recovery of waste oil-in-water drilling fluid: (a) waste drilling fluid; (b1), (b2) three-phase separation; (c) oil-water separation. 
Table 2. Contents of Waste Oil-in-water Drilling Fluid Components after Treated (w, \%)

\begin{tabular}{cccc}
\hline Phases after disposal & Water content & Oil content & Solid content \\
\hline oil phase & 0.00 & 99.94 & 0.06 \\
water phase & 97.52 & 2.18 & 0.30 \\
solid phase & 63.09 & 4.77 & 32.14 \\
\hline
\end{tabular}

Table 3. Properties Evaluation and Comparison of Drilling Fluid Prepared by Recycled Oil

\begin{tabular}{|c|c|c|c|c|c|c|}
\hline \multirow{2}{*}{ Type of oil } & \multicolumn{6}{|c|}{ Properties of drilling fluid } \\
\hline & AV, mPa.s & PV, mPa.s & YP, Pa & $\rho, \mathbf{g} / \mathbf{c m}^{3}$ & APL.FL, mL & Filtrate pH \\
\hline 0\# diesel & 33.5 & 22 & 11.5 & 0.93 & 6.8 & $9-10$ \\
\hline reclaimed oil & 35.0 & 23 & 12.0 & 0.97 & 7.4 & $9-10$ \\
\hline NP36-P3002 well drilling fluid design (5,957-6,470 m) & / & $20-22$ & $10-12$ & $0.96-0.98$ & $\leq 5$ & $10-12$ \\
\hline
\end{tabular}

AV: Apparent Viscosity

PV: Plastic Viscosity

YP: Yield Point

API.FL: American Petroleum Institute Filtration Loss

Table 4. The Main Pollutants in Middle Layer Wastewater $(\mathrm{mg} / \mathrm{L})$

\begin{tabular}{ccccccccc}
\hline Samples & $\mathbf{p H}$ & $\mathbf{C O D}$ & $\mathbf{C r}$ & $\mathbf{P b}$ & As & Hg & Cd & Oil \\
\hline wastewater before disposal & 7 & 993 & 0.19 & 0.08 & $/$ & $/$ & 0.01 & 21,800 \\
wastewater after disposal & 7 & 89 & 0.13 & 0.05 & $/$ & $/$ & 0.01 & 3.6 \\
GB8978 (grade one) & $6-9$ & 100 & 1.5 & 1 & 0.5 & 0.05 & 0.1 & 5 \\
\hline
\end{tabular}

collaboration demulsification technology. Oil content in water and solid was $2.18 \%$ and $4.77 \%$ respectively, which was convenient to later treated, while the oil recovery rate is more than $90 \%$ with no water and high purity. The goal of resource recovery on waste oil-in-water drilling fluid can be achieved.

\subsection{Reusing of Recycled Oil}

To verify the feasibility of preparing drilling fluid from recycled oil of waste oil (diesel)-in-water drilling fluid, the experiment of preparing drilling fluid from recycled oil was made. The results were shown in Table 3 indicating that (1) The properties of drilling fluid prepared by recycled oil is closed to $0^{\#}$ diesel, which verified recycled oil can be used for the preparation of drilling fluid; (2) Compared with NP36-P3002 well drilling fluid design, except for the water loss of the drilling fluid prepared from recycled oil was a little higher than the requirements of the design (which is associated with the dosage of filtrate reducer), the other properties can meet the demand of the design. The water loss of the drilling fluid can be reduced by adjusting filtrate reducer dosage in oilfield.

\subsection{Treatment of Middle Layer Wastewater}

Main pollutants in waste oil-in-water drilling fluid of middle layer wastewater after oil-water-solid three-phase separation were analyzed. The results were shown in Table 4 indicating that the heavy metal content and the $\mathrm{pH}$ value in the wastewater produced by waste oil-in-water drilling fluid after oil recovery can meet the requirements of grade one of "The National Integrated Wastewater Discharge Standard" (GB8978), but COD and oil is higher than standard limited value, which need further treated.

The method of flocculation oxidation can be used for the treatment of wastewater. First adding flocculant to reduce COD, then the Fenton reagent oxidation was used to further reduce the COD. Therefore, the treated water can reach national discharge standard.

The proper operation conditions for wastewater treatment were as follows: Polyaluminium chloride (PAC) dosage 1\%, room temperature, stirring time for $15 \mathrm{~min} ; \mathrm{H}_{2} \mathrm{O}_{2} / \mathrm{Fe}^{2+}=3.5: 1$, stirring time for $30 \mathrm{~min}$. Wastewater after treatment was analyzed. The results were shown in Table 4, which indicated that the COD and oil can meet the first grade of national standard (GB8978).

\subsection{Harmless Treatment of Sludge}

The sludge in waste oil-in-water drilling fluid after oil-water-solid three-phase separation was analyzed and the results were shown in Table 5, indicating that the heavy metal in the sludge can meet the requirements of "Control Standards for Pollutants in Sludge from Agricultural Use" (GB4284), while the oil content is up to $47,700 \mathrm{mg} / \mathrm{kg}$, higher than standard limit: $3,000 \mathrm{mg} / \mathrm{kg}$, which need further treated.

Harmless treatment experiment of sludge was performed adopting new harmless treating agent composed of curing agent and reinforcing agent. The proper indoor conditions for the treatment of sludge were as follows: curing agent concentration $3 \% \mathrm{w} / \mathrm{w}$, reinforcing agent concentration $10 \% \mathrm{w} / \mathrm{w}$. At room temperature, the sludge was solidified for $7 \mathrm{~d}$, then the lixivium of sludge cured product was measured. The results were shown in Fig. 2 and Table 6 indicating that the lixivium was colorless and trans 
Table 5. The Main Pollutants in the Sludge $(\mathrm{mg} / \mathrm{kg}, \mathrm{mg} / \mathrm{L})$

\begin{tabular}{ccccccc}
\hline Items & Oil & Cr & Cd & Pb & As & Hg \\
\hline testing value & 47,700 & 12.9 & 2.04 & 0.52 & 6.2 & 0.12 \\
GB4284 (grade one) & 3,000 & 75 & 20 & 15 & 1,000 & 1,000 \\
\hline
\end{tabular}

Table 6. The main pollutants in the lixivium of sludge cured product $(\mathrm{mg} / \mathrm{L})$

\begin{tabular}{cccccccccc}
\hline Items & $\mathbf{p H}$ & $\mathbf{C O D}$ & Oil & Cr & Cd & Pb & As & Hg \\
\hline testing value & 8 & 76.0 & 4.2 & 0.69 & 0.023 & 0.81 & 0.017 & 0.0093 \\
GB8978 (grade one) & $6-9$ & $\leq 100$ & $\leq 5$ & $\leq 1.5$ & $\leq 0.1$ & $\leq 1.0$ & $\leq 0.5$ & $\leq 0.05$ \\
\hline
\end{tabular}
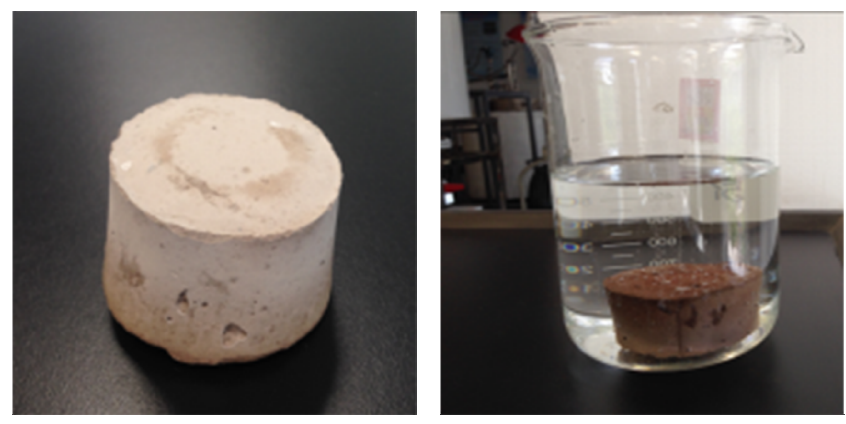

Fig. 2. Sludge after solidification and its lixivium.

parent after solidification treatment. $\mathrm{pH}$ value, COD, oil and heavy metals can meet the requirements of grade one of "The National Integrated Wastewater Discharge Standard” (GB8978). So good effects of harmless treatment on sludge can be achieved. will not be caused.

\section{Conclusions}

The Composition of waste oil-in-water drilling fluid from well NP361 in JiDong oilfield was analyzed, water content was 51.83\%; oil content was $38.14 \%$; sludge content was $10.03 \%$, high oil content gives a value to be recycled.

Physical-chemical collaboration demulsification technology was used for treatment of waste oil-in-water drilling fluid. The oil recovery rate was more than $90 \%$ after oil-water-solid three-phase separation. The water loss in the drilling fluid prepared by recycled oil was a little higher than the design criteria, the other properties index can meet the demand of the design.

Harmless treatment technology of middle layer wastewater and sludge in waste oil-in-water drilling fluid after oil recovery was studied. The wastewater after treated was clean, COD and oil can meet the first grade of national standard (GB8978); the lixivium in the sludge after solidification was colorless and transparent, $\mathrm{pH}$ value, COD, oil and heavy metals can meet the requirements of grade one of "The National Integrated Wastewater Discharge Standard” (GB8978).

\section{Acknowledgements}

The authors greatly appreciate financial support from Scientific
Research Development Foundation of Engineering and Technology College (2016KY09).

\section{References}

1. Dina K, Robiah Y, Rozita O. A review of biolubricants in drilling fluids: Recent research, performance, and applications. J. Petrol. Sci. Eng. 2015;135:177-184.

2. Huo BY, Peng SP, Yu ZG. Application of high-density oil-in-water drilling fluid in deep horizontal wells of Chuanxi. Drilling Fluid \& Completion Fluid 2013;30:45-48.

3. Li JC, Yang P, Guan J. A new type of whole oil-based drilling fluid. Petrol. Explor. Dev. 2014;41:538-544.

4. Dias FTG, Souza RR, Lucas EF. Influence of modified starches composition on their performance as fluid loss additives in invert-emulsion drilling fluids. Fuel 2014;140:711-716.

5. Han LS, Zhang JY, Cui HD. Application of oil-in-water fluid in fifth interval of well NP23-P2002. Drilling Fluid \& Completion Fluid 2011;28:36-39.

6. Wang W, Zhao YG, Li ZW. Application of high temperature resistant diesel in water drilling fluid in NP36-P3002 well. Drill. Prod. Technol. 2015;40:99-103.

7. Ren YJ, Jiang GC, Li FX. Cleanup characteristics and mechanisms of reversible invert emulsion drilling fluid. J. Petrol. Eng. 2015;133:296-303.

8. Davies JM, Addy JM, Blackman RA. Environmental effects of the use of oil-based drilling muds in the North Sea. Mar. Pollut. Bull. 1984;15:363-370.

9. Ayotamuno MJ, Olparanma RN, Ogaji SOT. Chromium removal from flocculation effluent of liquid-phase oil-based drill-cuttings using powdered activated carbon. Appl. Energ. 2007;84:1002-1011.

10. Robinson JP, Snape CE, Kingman SW. Thermal desorption and pyrolysis of oil contaminated drill cuttings by microwave heating. J. Anal. Appl. Pyrol. 2008;81:27-32.

11. Xie SX, Jiang GC, Chen M. Using chemical strengthening separation-harmless technology for the treatment of waste oil-based drilling fluid. Chinese J. Environ. Eng. 2011;5:425-430.

12. Liu YC, Xu JZ, Yuan JM. Experiment on thermo-chemical demulsification and centrifugal separation of abandoned oil-based drilling fluid. Chinese J. Environ. Eng. 2013;7:2333-2337.

13. Zhou JL, Yue QS, Yang LP. Soild-liquid separation technology of waste drilling fluid in offshore oilfields. J. Oil Gas Technol. 2012;34:148-151. 